\title{
A abordagem de conteúdos de Matemática em Práticas de Modelagem e as implicações para o currículo
}

\author{
Regina Helena de Oliveira Lino Franchi
}

\section{Resumo}

Neste artigo objetiva-se refletir sobre a abordagem de conteúdos de Matemática em práticas de Modelagem ${ }^{27}$ e a relação que se estabelece com os currículos estruturados para a educação escolar. A reflexão se dá a partir da dinâmica de uma prática de Modelagem com alunos de Licenciatura em Matemática e Química, a partir de um projeto temático. Enfoca como os conteúdos matemáticos foram abordados a partir das oportunidades que se apresentaram nos contextos estudados. A análise evidenciou a possibilidade de se abordar os conteúdos matemáticos de maneira contextualizada, mesmo que não previstos para aquele nível de escolaridade, ou mesmo que conteúdos considerados pré-requisitos não tenham sido trabalhados previamente. Dessa forma apresenta a possibilidade de rompimento com a linearidade dos programas, por meio da adoção de formas flexíveis e não lineares de organização curricular.

Palavras-chave: Modelagem Matemática, matemática escolar, currículo flexível.

${ }_{27}$ Neste artigo serão usadas indistintamente as palavras Modelagem e Modelagem Matemática, evitando repetição. Usarei letra maiúscula para me referir à Modelagem como proposta pedagógica ou área de pesquisa e letra minúscula para me referir ao processo de modelagem ou de construção de modelos. 


\section{The appoach of Mathematical contents in Modelling Practices and implications for curriculum}

\section{Regina Helena de Oliveira Lino Franchi}

\section{Abstract}

This article aims a reflection about approaching the mathematical contents in Modelling practices and the relation that is established with the structured curricula for school education. The reflection is based on dynamics of a Modelling practice with undergraduate students in Mathematics and Chemistry, developing a thematic project. It focuses on how the mathematical contents were approached from the opportunities presented in the contexts studied. The analysis showed the possibility of approaching the mathematical contents in a contextualized manner, even if not foreseen for that schooling cycle, or even if the mathematical contents considered prerequisites have not been previously worked on. In this way it presents the possibility of breaking with the linearity of the programs, through the adoption of flexible and non-linear forms of curricular organization.

Keywords: Mathematical Modelling, mathematics school, flexible curriculum. 


\section{Introdução}

Muito se tem discutido sobre as possibilidades de utilização da Modelagem Matemática em contextos escolares e sobre a sua caracterização na Educação Matemática. Há estudos a respeito de experiências de utilização da Modelagem, focalizando as maneiras de conduzir as atividades, a atuação dos alunos e dos professores nesse contexto, evidenciando uma diversidade de abordagens e perspectivas diferenciadas para a Modelagem no âmbito educacional. Há também o interesse de muitos pesquisadores em entender ou estabelecer possíveis conexões entre a Modelagem Matemática e outros enfoques ou áreas de pesquisa como Resolução de Problemas, Educação Matemática Crítica, Tecnologias Digitais, Organização e Desenvolvimento Curricular e Interdisciplinaridade.

Neste estudo, de cunho qualitativo, busquei estabelecer conexões entre as práticas de Modelagem e os currículos estruturados para a educação escolar. Para tanto examinei uma prática de Modelagem realizada em um curso de Licenciatura de Matemática e Química de uma escola privada. Busquei identificar as possibilidades de abordagem de conteúdos matemáticos que se apresentaram durante o desenvolvimento dessa prática e de que maneira se relacionaram com o currículo escolar. Foram considerados os registros das atividades desenvolvidas pelos participantes e as notas de campo do pesquisador. A apresentação e a análise sobre a prática de Modelagem enfatizam os aspectos da abordagem dos conteúdos de Matemática, embora as atividades tenham sido desenvolvidas também com outros objetivos, sobretudo os ligados à interdisciplinaridade e à Educação Matemática Crítica.

No contexto da Educação Matemática, entendo que a Modelagem Matemática é uma proposta pedagógica caracterizada pela criação de ambientes para investigação sobre um tema ou situação-problema através da Matemática, possibilitando a aprendizagem da Matemática, o desenvolvimento de potencialidades do estudante, bem como de sua capacidade de reflexão crítica no contexto do tema ou situação-problema investigados. A aprendizagem da Matemática pode se dar a partir das representações feitas, das ferramentas ou métodos matemáticos utilizados na busca de soluções para as problemáticas formuladas. A participação ativa do estudante no processo de modelagem pode estimular o desenvolvimento de potencialidades tais como a iniciativa, criatividade, criticidade, autonomia para aprender, capacidade de trabalhar em equipe, de buscar informações e de utilizar recursos variados para solução de problemas.

Para a sala de aula é recomendável que os temas investigados sejam de interesse dos estudantes e, preferencialmente escolhidos por eles, muito embora também alguns autores admitam a possibilidade dos temas serem propostos ou negociados com o professor. Considerações sobre a Modelagem desenvolvida a partir de temas podem ser encontradas em Bassanezi (2002), Franchi (2002, 2007), Burak (2004, 2010), Barbosa (2003), Meyer, Caldeira e Malheiros (2011), Biembengut (2014, 2016), entre outros. Uma vez decididos os 
temas, iniciam-se pesquisas exploratórias ou de campo, realizam-se discussões relativas aos temas e identificam-se possíveis problemas a serem resolvidos. Um ou mais problemas são escolhidos e os estudantes, geralmente reunidos em grupos, iniciam estudos para buscar soluções aos problemas propostos.

Para Bassanezi (2002) a modelagem matemática de uma situação ou problema real envolve várias etapas que vão desde a formulação do problema em linguagem natural, a identificação das variáveis envolvidas, a escolha das que interferem significativamente no problema e se deseja considerar, a formulação do problema em linguagem matemática, a escolha das ferramentas matemáticas a serem utilizadas, a própria resolução, a validação das soluções obtidas, a modificação do modelo (se necessário), a interpretação das soluções no contexto do problema e a possível aplicação das soluções.

Particularmente nas etapas de formulação e resolução dos problemas, podem ser necessários conceitos e técnicas matemáticas, conhecidos pelos participantes ou não. Quando as atividades são desenvolvidas a partir de temas ou mesmo de situações-problema apresentadas pelo professor, é possível, de certa maneira, ter uma previsão do tipo de conteúdo matemático necessário ou interessante para aquele contexto. Dessa forma o professor, planejando a atividade com antecedência, pode escolher as situações adequadas àquele nível de escolaridade e que certamente levarão ao aparecimento de conteúdos já trabalhados ou daqueles que se pretende introduzir naquele momento. Em Franchi e Bean (2011) encontra-se um exemplo em que é proposto o planejamento de uma reforma de um espaço de convivência, tendo como um dos objetivos a abordagem de conteúdos relativos a números racionais. Ao terem que estudar possibilidades para escolha de materiais e mão de obra, muitas medidas e cálculos têm que ser feitos e o conteúdo matemático é contemplado.

No entanto, quando o trabalho é desenvolvido a partir de temas escolhidos pelos participantes, nem sempre se pode prever o que efetivamente acontecerá durante o processo de modelagem e quais conteúdos matemáticos aparecerão. Caso os conteúdos ou métodos necessários sejam conhecidos, podem ser utilizados e ressignificados naquele contexto. Caso não sejam de conhecimento dos participantes, podem ser trabalhados com a orientação do professor, a partir das necessidades do processo de modelagem.

Em ambas as situações a Modelagem se configura como uma estratégia para aprendizagem da Matemática. A aprendizagem está aqui entendida não apenas como construção de um conhecimento novo, mas também como a habilidade de mobilizar conhecimentos para aplicar em novos contextos, nos quais eles podem ter outros significados. Em Franchi (1993) é possível identificar um exemplo em que estudantes de engenharia, após visita a uma indústria, escolheram, entre outros problemas, entender como se dá o resfriamento de peças retiradas de um forno de fundição. Nessa situação utilizaram a derivada 
para equacionar o resfriamento, sendo possível, a partir daí, introduzir o conceito de equação diferencial e trabalhar a resolução por separação de variáveis.

Nesse cenário é possível caracterizar duas situações distintas: o desenvolvimento de atividades de Modelagem Matemática como possibilidade de aplicar e resignificar conteúdos matemáticos já trabalhados (no caso, o conteúdo de Derivadas) e a Modelagem como oportunidade de abordar novos conteúdos (no caso, as equações diferenciais). A primeira situação é aceita com mais tranquilidade mesmo pelos que acreditam que os conteúdos sempre devem ser trabalhados previamente para depois os estudantes utilizarem nos modelos. Já na segunda situação, admite-se a possibilidade dos conteúdos serem trabalhados com os alunos durante o processo de modelagem e isso às vezes é visto com restrições por alguns professores que tentam desenvolver práticas de Modelagem em suas aulas. Há os que acreditam que, o fato de os participantes não conhecerem previamente os conteúdos matemáticos necessários, pode prejudicar o processo de resolução do problema. Há os que acreditam que os conteúdos podem ser desenvolvidos a partir do modelo, mas que o distanciamento temporário do problema, necessário para sistematização dos conceitos matemáticos, pode gerar desinteresse dos participantes. Há ainda os que se preocupam com o cumprimento dos programas préestabelecidos, ou com o fato de que os conceitos necessários podem ser diferentes dos previstos para aquela etapa ou mesmo que não seja possível trabalhar aqueles conceitos pela sua eventual complexidade ou por falta de pré-requisitos.

Defendo que o conteúdo matemático, por si só, não deve se configurar como restrição para a Modelagem. Pelo contrário, ao possibilitar a abordagem de conceitos novos, em níveis de complexidade que até então não tinham sido tratados, a Modelagem pode ser uma oportunidade de flexibilização do currículo e rompimento com a linearidade dos programas das disciplinas ou dos cursos. E isso se mostra interessante principalmente em um momento onde as novas gerações convivem com espaços de conhecimento compartilhados e multifacetados. Essa visão, tão pertinente para o momento atual, já era apresentada por Levy (1999):

Devemos construir novos modelos do espaço dos conhecimentos. No lugar de uma representação em escalas lineares e paralelas, em pirâmides estruturadas em "níveis", organizadas pela noção de pré-requisitos e convergindo para saberes "superiores", a partir de agora devemos preferir a imagem de espaços de conhecimentos emergentes, abertos, contínuos, em fluxo, não lineares, se reorganizando de acordo com os objetos ou os contextos, nos quais cada um ocupa uma posição singular e evolutiva.(...) Mas o essencial se encontra em um novo estilo de pedagogia, que favorece ao mesmo tempo as aprendizagens personalizadas e a aprendizagem coletiva em rede. Nesse contexto, o professor é incentivado a tornar-se um animador da inteligência coletiva de seus grupos de alunos em vez de um fornecedor direto de conhecimentos (LÉVY, 1999, p. 158). 
A prática descrita e comentada a seguir exemplifica uma situação em que conteúdos matemáticos não previstos para aquela etapa foram trabalhados, a partir de necessidades emergentes do processo de investigação da situação em estudo.

\section{A prática de Modelagem: motivação e encaminhamento}

A atividade objeto desta reflexão foi desenvolvida no âmbito de uma disciplina denominada Resolução de Problemas III, oferecida para alunos dos cursos de Licenciatura em Matemática e Licenciatura em Química, em uma universidade privada. Embora o foco de discussão deste artigo esteja nas questões relacionadas aos conteúdos matemáticos emergentes dos estudos realizados, julgo importante relatar, mesmo que de forma breve, as características do conjunto de disciplinas "Resolução de Problemas" que compunham o currículo naquele momento e as atividades desenvolvidas ${ }^{28}$ nas disciplinas Resolução de Problemas I e II, que antecederam à atividade em questão.

Integravam a grade curricular dos referidos cursos de cinco disciplinas, denominadas Resolução de Problemas, com duas horas-aula semanais cada, oferecidas sequencialmente a partir no primeiro semestre dos cursos. Os objetivos dessas disciplinas eram desenvolver estudos de fenômenos que permitissem a articulação das diferentes áreas de conhecimento (representadas pelas diferentes disciplinas do semestre) e promover a integração entre os dois cursos (Matemática e Química). Além das reflexões a respeito dos temas abordados, as disciplinas deveriam também propiciar o resgate de conceitos matemáticos considerados básicos, tanto para a própria área de Matemática, como para as áreas de Física e Química, que compunham a parte de formação básica dos currículos dos cursos em questão.

Na disciplina Resolução de Problemas I, os participantes foram convidados a refletir sobre o fenômeno do aquecimento global. O convite à reflexão tem aqui o sentido de tentar constituir um cenário para investigação, caracterizado por Skovsmose (2000) como o ambiente de aprendizagem que favorece abordagens investigativas. $O$ tema foi colocado previamente pelo professor e foi pensado como promissor, pela possibilidade das reflexões críticas sobre o tema em si, bastante veiculado pela mídia, mas também por possibilitar a formulação de problemas que provavelmente se relacionariam a diferentes áreas de conhecimento, como era o objetivo da disciplina.

$\mathrm{O}$ tema despertou o interesse dos participantes. Individualmente realizaram pesquisas teóricas, que posteriormente foram apresentadas e debatidas com o conjunto dos participantes em plenária realizada em sala. Foi possível identificar que parte das ações humanas, rotineiras ou relacionadas ao sistema produtivo, resulta na emissão de poluentes

${ }^{28}$ Essas atividades foram parcialmente descritas em Franchi (2013), porém a abordagem feita enfocou aspectos diferentes dos tratados neste artigo. 
atmosféricos através de gases que contribuem para o efeito estufa e para o aquecimento global. Entre os gases que contribuem para o efeito estufa, destaca-se o dióxido de carbono $\left(\mathrm{CO}_{2}\right)$.

Decidiu-se, com o grupo, estudar como se dá a absorção e a emissão de $C O_{2}$ no ambiente. Entendendo que uma melhora do quadro global depende de ações individuais e coletivas, iniciamos estudos que permitissem melhor compreensão do problema localmente. Assim decidiu-se focar o estudo na cidade, na qual se localiza a universidade em questão, que tem economia vinculada à produção agrícola, com destaque para o setor sucroalcooleiro e à produção industrial. As atividades da disciplina foram então planejadas para estudar como se dá a absorção de $\mathrm{CO}_{2}$, buscando quantificar a absorção na cidade no ano anterior ao desenvolvimento do Projeto de Modelagem. Ao mesmo tempo, os estudantes divididos em grupos elaboraram projetos, que foram desenvolvidos no semestre seguinte (na disciplina Resolução de Problemas II) com o objetivo de quantificar a emissão de $\mathrm{CO}_{2}$ na cidade no mesmo período.

Os estudos iniciais se desenvolveram no sentido que compreender o fenômeno de fotossíntese através do qual se caracteriza a absorção de $\mathrm{CO}_{2}$ pelas plantas. Com a participação efetiva de estudantes da sala, que tinham conhecimentos na área de Química, foram estudadas as equações químicas correspondentes ao fenômeno em questão. Considerando que a área ocupada por canaviais é bastante significativa no município, criou-se a expectativa que a absorção do gás dióxido de carbono pela massa vegetativa do bioma fosse maior que a emissão decorrente das atividades rotineiras e industriais da cidade.

Para a elaboração de um modelo que permitisse quantificar a absorção de $\mathrm{CO}_{2}$ na cidade no período em questão, consideramos o modelo químico da reação de fotossíntese e as características da planta da cana com relação à sua composição e optamos por nos restringirmos aos dados relativos às áreas das plantações de cana de açúcar no município, no ano estudado. Isso porque os estudantes consideraram a área plantada com cana significativamente maior que as demais áreas plantadas. Foram então quantificados os valores de $\mathrm{CO}_{2}$ absorvidos no ano em questão.

Em seguida, iniciamos a elaboração de projetos a serem desenvolvidos no semestre seguinte, com o objetivo de elaborar um modelo para a emissão de $\mathrm{CO}_{2}$ na cidade, e através dele quantificar a emissão no mesmo período. Os projetos para a elaboração do modelo de emissão foram desenvolvidos na disciplina Resolução de Problemas II, no semestre seguinte. Para o modelo de emissão, foram consideradas: as emissões decorrentes da queima de combustíveis pelos veículos, as emissões animal e humana (decorrentes da respiração), as resultantes das atividades de indústrias siderúrgicas e cerâmicas, as decorrentes da queima da palha da cana-de-açúcar (atividade então existente na cidade, pois a cana era queimada antes ISSN 2526-2882

$$
\text { * } 205
$$


de ser colhida) e as resultantes da fermentação da cana que ocorre nas usinas de produção de açúcar e álcool. As atividades foram desenvolvidas em grupos, sendo cada grupo responsável por um dos setores escolhidos. Com base nos modelos de cada setor, foi possível quantificar a emissão total da cidade no período considerado.

Comparando os resultados obtidos pelos modelos de emissão e de absorção constatou-se que a emissão foi quantitativamente maior que a absorção. Esse resultado foi discutido com os participantes procurando identificar possíveis ações para enfrentar esse problema. Percebeu-se que as soluções demandam políticas ambientais e amplas ações de controle. No entanto, a conscientização de cada um para o problema pode gerar ações individuais que contribuam para modificação desse cenário.

Da consciência da responsabilidade de cada um diante do contexto e estimulados por uma reportagem sobre uma ação de reflorestamento desenvolvida com o objetivo de neutralizar emissões de $\mathrm{CO}_{2}$, surgiu a ideia de buscar alternativas para tentar neutralizar as emissões de $\mathrm{CO}_{2}$, decorrentes das ações cotidianas daquele grupo, através do plantio de árvores, possibilidade esta apontada na literatura como alternativa de ação individual. Esse foi o trabalho desenvolvido na disciplina Resolução de Problemas III, no semestre seguinte. Especificamente sobre essa prática, neste artigo será apresentada a maneira como os conteúdos matemáticos foram trabalhados.

Inicialmente buscamos identificar as variáveis mais significativas para a quantificação da emissão dos participantes do projeto, de modo individual. A seleção das variáveis a serem consideradas se deu com base em pesquisas bibliográficas e orientações de diferentes sites, conhecidos como "calculadoras de $\mathrm{CO}_{2}$ ". Estes sites calculam a quantidade de $\mathrm{CO}_{2}$ emitida, com base em informações que o usuário dá a respeito de suas atividades rotineiras como, por exemplo, consumo de combustíveis, energia, entre outros. Muitos deles também dão uma estimativa do número de árvores a serem plantadas para neutralizar a emissão calculada.

Examinamos vários destes sites, identificamos os diferentes parâmetros apresentados em cada um e optamos por considerar os seguintes itens: deslocamento em diferentes tipos de veículos automotores, consumo de eletricidade, consumo de gás liquefeito de petróleo e quantidade de lixo (não reciclável) produzido. Coletamos informações referentes às atividades de uma semana de todos os elementos do grupo. Esses dados foram organizados em uma planilha, preservando os dados individualmente e também estimando a média do grupo, para o período de um ano.

Para o cálculo do $\mathrm{CO}_{2}$ emitido foram selecionados cinco sites para serem testados com determinado conjunto de dados e foram escolhidos os três sites ${ }^{29}$ que apresentaram

29 Os sites escolhidos foram: www.florestasdofuturo.org.br; www.keyassociados.com.br; ISSN 2526-2882 
resultados mais próximos. Estimamos então a emissão média por pessoa do grupo, como a média aritmética dos valores apresentados pelos três sites selecionados.

Com relação ao número de árvores a ser plantado, houve grande diferença nas respostas dos diferentes sites. O grupo decidiu estudar como esse cálculo pode ser feito. Novamente recorremos a pesquisas bibliográficas e à ajuda de especialistas na área. Uma agrônoma foi convidada a dar uma palestra ao grupo. Nessa palestra foram apresentadas algumas formas de estimar o carbono fixado nas plantas, formas estas relacionadas ao tipo de árvore, altura, tamanho do fuste ${ }^{30}$, volume e densidade da madeira. Foram também discutidas as diferentes espécies de árvores adequadas para reflorestamento. O eucalipto, pelas suas características de rápido crescimento e alta produtividade, foi indicado como alternativa viável. A palestrante indicou artigo de Soares e Oliveira (2002) em que é proposto um modelo matemático para estimar a quantidade de carbono na parte aérea de árvores de eucalipto. $\mathrm{O}$ artigo descrevia algumas etapas do estudo feito, apresentava dados experimentais e trazia a solução na forma de uma função. No entanto o artigo não trazia a explicação de como aquela expressão havia sido obtida. Instigados pelo professor, os estudantes decidiram entender como esse modelo havia sido construído.

\section{O trabalho com o modelo e com os conteúdos matemáticos}

Em um primeiro momento buscamos entender as etapas apresentadas na pesquisa em questão, a saber: primeiramente foram coletadas amostras de eucalipto, caracterizadas de acordo com a espécie, idade, diâmetro do fuste a 1,30m (dap), altura total (Ht). Das árvores selecionadas foram elaboradas amostras de folhas, galhos e fuste. Por diferentes processos experimentais foi calculada a biomassa de cada uma das amostras. A estimativa da quantidade de carbono presente em cada conjunto (folhas, galhos, fuste com e sem casca) das árvores das amostras foi obtida multiplicando a estimativa de biomassa por 0,5 , considerando que em média 50\% da biomassa é carbono.

Os dados experimentais mostraram que o fuste é o componente da parte aérea da árvore com maior quantidade de carbono estocado (83\%). Gráficos de dispersão para a quantidade de carbono em função do dap para cada tipo de amostra, construídos com base nestes dados e apresentados no referido artigo, indicaram haver uma relação exponencial entre a quantidade de carbono presente nas diferentes partes da árvore (Y) e o tamanho das árvores (dap). Essa relação foi representada pela equação (1), fazendo referência a uma relação alométrica apontada na literatura:

$$
Y=a \cdot(\text { dap })^{b}
$$

www iniciativaverde.com.br.

${ }^{30}$ Fuste é a parte mais visível do tronco de uma árvore, situada entre o solo e as primeiras ramificações. ISSN 2526-2882 
Há no artigo a informação de que árvores com mesmo diâmetro podem ter diferentes quantidades de carbono, em função de suas alturas, formatos de fustes e localização. A inclusão da influência da altura total da árvore (Ht) foi apresentada como alternativa para melhorar o modelo. Assim, a expressão fica redefinida como:

$$
Y=a \cdot(\text { dap })^{b}(H t)^{c}
$$

O artigo não explica porque o modelo considerou variação exponencial também para a altura, mas, caracteriza a expressão (2) como uma variação de um modelo que considera o volume dos troncos das árvores individualmente. Uma interpretação possível, não apresentada no artigo, é que a relação direta do produto dap.Ht com o volume, bem como uma possível variação exponencial em relação ao volume no modelo citado, justifique a variação exponencial em relação à altura no modelo apresentado.

O método dos mínimos quadrados foi indicado no artigo para obtenção de uma equação linear e os valores obtidos pelo ajuste foram apresentados. Com o objetivo de entender como a expressão foi obtida, recorremos aos dados experimentais de dap(cm), altura $\mathrm{Ht}(\mathrm{m})$ e carbono (kg) para fuste, com e sem casca, apresentados no artigo para estimar os valores das constantes a, b e c da equação (2) acima. A aplicação de logaritmos permitiu estudar a função exponencial Y de duas variáveis a partir da função $\ln (\mathrm{Y})$, linear nos parâmetros e também a aplicação do método dos mínimos quadrados para o ajuste:

$$
\begin{aligned}
& \ln (Y)=\ln \left(\text { a. }(\text { dap })^{b}(H t)^{c}\right) \\
& \ln (Y)=\ln (a)+\ln (\text { dap })^{b}+\ln (H t)^{c} \\
& \ln (Y)=\ln (a)+b \cdot \ln (\text { dap })+c \cdot \ln (H t)
\end{aligned}
$$

Definimos:

$$
\begin{aligned}
& y=\ln (Y) \\
& a_{1}=\ln (a) \\
& a_{2}=b \\
& a_{3}=c \\
& g_{1}=1 \\
& g_{2}=\ln (\text { dap }) \\
& g_{3}=\ln (H t)
\end{aligned}
$$

Logo: $\quad \mathrm{y}=a_{1} g_{1}+a_{2} g_{2}+a_{3} g_{3}$

Os dados relativos ao carbono fixado Y, tamanho dap e altura Ht das 40 árvores, apresentados no artigo, foram tomados como vetores. Sendo $x_{i}$ a i-ésima árvore tem-se: 


$$
\begin{aligned}
& \text { Vetor } \mathbf{x}=\left(x_{1}, x_{2}, \ldots x_{40}\right) \\
& \text { Vetor } \mathbf{g} \mathbf{1}=(1,1, \ldots 1) \\
& \text { Vetor } \mathbf{g} \mathbf{2}=\left(\ln \left(\operatorname{dap}\left(x_{1}\right)\right), \ln \left(\operatorname{dap}\left(x_{2}\right)\right), \ldots \ln \left(\operatorname{dap}\left(x_{40}\right)\right)\right) \\
& \text { Vetor } \mathbf{g} \mathbf{3}=\left(\ln \left(H t\left(x_{1}\right)\right), \ln \left(H t\left(x_{2}\right)\right), \ldots \ln \left(H t\left(x_{40}\right)\right)\right) \\
& \text { Vetor } \mathbf{y}=\left(y_{1}, y_{2}, \ldots, y_{40}\right)=\left(\ln \left(Y\left(x_{1}\right)\right), \ln \left(Y\left(x_{2}\right)\right), \ldots \ln \left(Y\left(x_{40}\right)\right)\right)
\end{aligned}
$$

O sistema de equações, relativo à aplicação do método dos mínimos quadrados para funções lineares nos parâmetros, pode ser representado através da equação matricial:

$$
\left[\begin{array}{lll}
g 1 . g 1 & g 1 . g 2 & g 1 . g 3 \\
g 2 . g 1 & g 2 . g 2 & g 2 . g 3 \\
g 3 . g 1 & g 3 . g 2 & g 3 . g 3
\end{array}\right] \cdot\left[\begin{array}{l}
a_{1} \\
a_{2} \\
a_{3}
\end{array}\right]=\left[\begin{array}{l}
g 1 . y \\
g 2 . y \\
g 3 . y
\end{array}\right]
$$

A notação “.” apresentada na equação matricial refere-se ao produto escalar dos vetores em questão. Os produtos escalares foram calculados através de planilhas montadas em Excel. Foram obtidos ajustes considerando o fuste com e sem casca.

Para o fuste sem casca tem-se:

$$
\left[\begin{array}{ccc}
40,0000000 & 105,0575000 & 123,9092000 \\
105,0575000 & 282,8150107 & 329,8094316 \\
123,9092000 & 329,8094316 & 386,8585876
\end{array}\right] \cdot\left[\begin{array}{l}
a_{1} \\
a_{2} \\
a_{3}
\end{array}\right]=\left[\begin{array}{l}
135,9867000 \\
374,8438864 \\
434,2338539
\end{array}\right]
$$

Da resolução do sistema tem-se:

$a_{1}=-6,962241207, a_{2}=1,59148434$ e $a_{3}=1,995646669$

Então:

$$
\begin{aligned}
& \mathrm{y}=a_{1} g_{1}+a_{2} g_{2}+a_{3} g_{3} \\
& \mathrm{y}=-6,962241207 g_{1}+1,59148434 g_{2}+1,995646669 g_{3}
\end{aligned}
$$

Como $\ln (Y)=\ln (a)+b \cdot \ln ($ dap $)+c \cdot \ln (H t)$, tem-se:

$$
\ln (Y)=-6,962241207+1,59148434 \cdot \ln (\text { dap })+1,995646669 \cdot \ln (H t)
$$

Então, $\ln (a)=-6,962241207 \Rightarrow e^{-6,962241207}=a \Rightarrow a=0,000957$ 


$$
\begin{aligned}
& b=1,59148434 \\
& c=1,995646669
\end{aligned}
$$

A função que permite estimar a quantidade Y (em kg) de carbono absorvido pelas árvores de eucalipto, escrita como função do tamanho dap (em $\mathrm{cm}$ ) e da altura $\mathrm{Ht}$ (em m), considerando o fuste sem casca é dada por:

$$
Y_{s c}=0,000957(\text { dap })^{1,59148434}(\boldsymbol{H t})^{1,995646669}
$$

De forma análoga obteve-se a função considerando o fuste com casca:

$$
Y_{c c}=0,001287(\text { dap })^{1,63209363}(H t)^{1,89135288}
$$

As expressões obtidas foram comparadas com as expressões apresentadas no artigo e os valores foram bastante próximos. Uma vez entendido o modelo, buscamos estimar a quantidade de árvores necessárias para neutralizar as emissões individuais e do grupo. Para o cálculo da quantidade de carbono absorvido foi considerado que uma árvore de eucalipto com melhoramento genético possui dap médio de 26,1cm e Ht médio de 31,5m. Assim:

$$
\begin{aligned}
& Y_{s c}=168,1014991 \mathrm{~kg} \\
& Y_{c c}=180,0953766 \mathrm{~kg}
\end{aligned}
$$

Optou-se por considerar o maior valor (referente ao fuste com casca) levando em conta que nos cálculos não foi considerada a quantidade de carbono absorvida pelas folhas, galhos e raízes, que a literatura apontou como pouco significativa em comparação com o fuste.

$\mathrm{O}$ número $\mathrm{N}$ de árvores é dado por:

$$
N=\frac{Q}{180,0953766} \text {, sendo Q a quantidade de CO2 emitido (em kg). }
$$

Assim, por exemplo, uma pessoa que emitiu $2000 \mathrm{~kg}$ de $\mathrm{CO} 2 \mathrm{em}$ um ano, deve plantar 11 árvores de eucalipto para neutralizar essa emissão. Apresento, a seguir, como os conteúdos matemáticos foram sistematizados à medida que se mostraram necessários no processo de modelagem.

\section{A Sistematização dos Conteúdos Matemáticos Emergentes do Processo de Modelagem}

Os estudantes participantes do trabalho tinham conceitos introdutórios de Cálculo Diferencial e Integral de funções de uma variável. Em algumas situações de Modelagem em que se opta por fazer ajustes, é possível trabalhar a ideia subjacente ao ajuste de curvas pelo método dos mínimos quadrados e fazer os possíveis ajustes através do Excel, sem necessariamente ter que entrar na discussão do método naquele momento. 
Isso porque a compreensão dos processos envolvidos no método querer a resolução de problemas de otimização (para minimizar distâncias) envolvendo também conceitos de derivadas parciais e resolução de sistemas lineares, que podem não ter sido trabalhados e o professor julgar que não é oportuno para aquele momento. Utilizar os recursos do Excel explicando a ideia subjacente viabiliza o tratamento matemático necessário naquele contexto, permitindo a continuidade do processo de modelagem.

No caso do modelo considerado para a absorção de $\mathrm{CO}_{2}$ em estudo, isso não foi possível, uma vez que o modelo indicado no artigo estabelecia a quantidade de carbono das plantas como uma função de duas variáveis, o que dificultou a obtenção da expressão apenas pela linha de tendência no gráfico de dispersão obtido pelo Excel, como no caso de funções de uma variável. Embora os conteúdos necessários não tivessem sido trabalhados previamente, iniciamos o estudo do ajuste pelo método dos mínimos quadrados.

Nessa etapa nos distanciamos temporariamente do problema original para fazer os estudos teóricos necessários. Tomando a condução do processo procurei formas de trabalhar a aplicação do método dos mínimos quadrados, enfatizando os conceitos necessários para compreensão do método e introduzindo a Matemática necessária, tendo como base os conhecimentos que os estudantes já tinham.

Dessa forma, considerando que a ideia subjacente ao método é minimizar distâncias, resgatei a forma utilizada para calcular mínimos de funções de uma variável e procurei fazer as extensões necessárias para duas variáveis. Retomei o cálculo de máximos e mínimos para funções de uma variável, usando o recurso de igualar a derivada a zero e em seguida trabalhei a mesma ideia para o caso de duas variáveis. Para tanto foi necessário introduzir o conceito de derivada parcial, o que foi feito de forma natural retomando o conceito e a definição matemática de funções de uma variável e fazendo a analogia para duas variáveis.

É importante destacar que em todos os estudos os conceitos fundamentais foram trabalhados embora os assuntos não tivessem sido esgotados com todos os desdobramentos em termos de técnicas e aplicações. No caso das derivadas parciais, o necessário para o método era saber derivar a função potência, composta. A forma de cálculo foi compreendida com facilidade pelos participantes a partir da analogia com a regra da cadeia para funções de uma variável.

Iniciamos o estudo do método dos mínimos quadrados pelos ajustes lineares para funções de uma variável. Equacionamos as funções relativas às somatórias dos quadrados das diferenças, calculamos as derivadas parciais, igualamos a zero, resolvemos o sistema de equações correspondente e obtivemos os coeficientes da reta (regressão linear). Essa abordagem permitiu que o conceito de ajuste fosse trabalhado e ao mesmo tempo permitiu a compreensão da forma como pode ser calculado pelas derivadas parciais. 
Esse estudo inicial foi o caminho usado para a generalização que nosso problema requeria. Com base no ajuste linear, fizemos ajustes exponenciais pela aplicação de logaritmos. Através da introdução do conceito de vetor pudemos representar os diferentes conjuntos de dados. As somatórias foram representadas como produtos escalares de vetores, operação esta também trabalhada no contexto pela primeira vez. O sistema de equações montado para os ajustes lineares foi, neste momento, representado por uma equação matricial. Essa estrutura foi tomada como base para generalização do método do ajuste para funções lineares nos parâmetros. Alguns exemplos de ajustes envolvendo diferentes tipos de funções foram trabalhados pelos estudantes.

De posse dos instrumentos necessários voltamos ao nosso problema original. A função exponencial, de duas variáveis, proposta como modelo para cálculo do carbono absorvido, poderia ser convertida em uma função linear nos parâmetros através da aplicação de logaritmos. E assim foi feito, como descrito anteriormente. Essa aplicação de logaritmos estava descrita no artigo, mas não fazia nenhum sentido para os alunos no momento que estudamos o artigo pela primeira vez. Após o estudo do método foi possível entender que a aplicação de logaritmos transformou a função em "linear nos parâmetros" possibilitando a determinação dos parâmetros através da resolução do sistema de equações lineares correspondente.

\section{Reflexões sobre Modelagem e Currículo a partir da Prática Desenvolvida}

Falar sobre currículo é inserir-se em uma discussão abrangente que envolve questões conceituais sobre seu significado e importância no processo educacional. A visão que trago à tona é a de que, ao longo da história, os currículos são concebidos levando em conta características e interesses de determinado contexto e que, subjacente à construção do currículo, estão concepções de educação e aprendizagem. Concordo com D’Ambrosio (1986, 1996) no seu entendimento de currículo como uma estratégia para ação educacional, sendo função do contexto e do momento social em que se insere. Sendo uma estratégia para ação educacional deve contemplar aspectos muito além da construção de grades de disciplinas e da determinação de seus conteúdos.

No cenário brasileiro atual, os currículos de diferentes segmentos educacionais, na sua maioria, são estruturados em disciplinas isoladas, com programas estabelecidos como se cada disciplina tivesse um fim em si mesma. Na prática, são essas grades e programas que guiam as atividades dos cursos em diferentes níveis. As disciplinas, que compartimentalizam o conhecimento, em geral são dispostas em uma ordem que deve ser seguida, de modo a garantir que o estudante em cada etapa tenha adquirido todos os pré-requisitos necessários para acompanhar o que se propõe naquele momento. Em geral os currículos são estáticos e inflexíveis. Meyer, Caldeira e Malheiros (2011) mencionam que professores dispostos a discutir 
na escola problemas advindos da realidade do aluno devem buscar estratégias para que o currículo de Matemática seja cumprido:

Aqui, entra uma questão fundamental, porque, se tiverem que cumprir o currículo, da maneira como ele está estruturado na escola, fragmentado, sequencialmente linear, imposto e, segundo Freire (1996), produzido em gavetas, de acordo com os anos de escolaridade e pronto para ser depositado nos alunos, poderão ter dificuldades. (p. 40)

Algumas metáforas têm sido usadas para representar concepções subjacentes a esse tipo de organização curricular. Uma delas é a "metáfora do balde" na qual se entende que o conhecimento vai sendo acumulado ao longo do tempo. Teriam então as diferentes disciplinas, durante os anos de escolarização, a função de ir enchendo esse balde. Outra é a "metáfora dos elos de uma corrente" na qual o conhecimento se constrói a partir de elos que estão interligados, em sequência. Faltando um dos elos o processo é rompido, impossibilitando a continuidade. Essa é a justificativa para a estrutura linear do currículo organizado por disciplinas encadeadas, cada uma delas com a função de permitir o acesso à etapa seguinte.

Machado (1995, p.188) faz uma crítica a essa organização que, de certo modo, ainda prevalece nos dias atuais:

De fato, internamente e no planejamento curricular, a forma de organização linear é amplamente predominante na organização do trabalho escolar, comprometendo-se muitas vezes desnecessariamente com uma fixação relativamente arbitrária de pré-requisitos e com uma seriação excessivamente rígida, que responde em grande parte pelos números inaceitáveis associados à repetência e à evasão escolares.

Outras formas de organização curricular têm sido apresentadas como alternativas ao modelo acima descrito. Ferreira (2007) indica que uma das possibilidades de organização do conhecimento curricular é a que se orienta para possibilitar aos indivíduos a busca de soluções para os problemas de seu entorno. "Uma organização do saber que reagrupe os saberes dispersos em disciplinas centradas nelas mesmas. Uma organização que tenha como objeto, não apenas, um setor ou uma parte, mas uma rede de conexões” (Ferreira, 2000, p.21).

Essa organização associa o currículo à "metáfora de rede" na qual os conhecimentos estão interligados, mas não há uma única forma de percurso. A ideia de rede se relaciona ao que Levy (1999) apresenta como hipertexto. Para Machado (2000) a ideia de rede ou teia de significados, na qual os currículos das diferentes disciplinas se entrelaçam, dá maior mobilidade ao currículo. Segundo o autor, não existe um centro no interior das redes e nem um único caminho a ser seguido. As redes podem ter muitos centros que se modificam com o contexto. Nas redes há muitas portas de entrada e muitos caminhos a serem percorridos. As 
redes não são imutáveis. Elas se transformam à medida que o conhecimento se constrói e se atualiza.

Pela natureza das atividades desenvolvidas, a Modelagem naturalmente exige a flexibilização da estrutura curricular linear, mostrando-se coerente com as características das estruturas em rede. Os processos de investigação sobre os temas e a procura de soluções para os problemas formulados exigem a mobilização de saberes, exigem tomada de decisões. Os participantes podem indagar: que conhecimentos eu preciso para entender ou resolver isso? Já possuo esses conhecimentos? Dos que possuo quais poderia usar? De que maneira? Se não possuo conhecimentos suficientes posso aprender agora? Onde poderia buscar? Que possibilidades se apresentam para resolução do problema? Que processo seria mais indicado?

Ambientes de aprendizagem que privilegiam a investigação, a reflexão, o diálogo e a cooperação devem admitir a possibilidade do currículo ser, de certa forma, gerido pelos participantes. Segundo Silva (2013, p.220) "seria recomendável dosar projetos que utilizem os conteúdos matemáticos como ferramenta de resolução de problemas ligados à realidade social, e, ao mesmo tempo, que valorizem os conteúdos puramente matemáticos, que despertem nos alunos o interesse por investigar a ciência Matemática [...]”. Ainda para Silva (2013) na disposição em rede (característica de um currículo pós-moderno) os objetivos, a seleção e o direcionamento de experiências são hipóteses que deverão ser reconstruídas e negociadas durante o processo.

A falta de abertura para enxergar alternativas e a extrema rigidez no cumprimento de programas faz com que muitas vezes deixemos escapar oportunidades de criar situações que propiciem que a aprendizagem ocorra de forma contextualizada e com significado para o estudante. Interpreto que a atividade de Modelagem que incluiu o estudo da absorção arbórea de $\mathrm{CO}_{2}$ descrito anteriormente foi uma boa oportunidade para introdução do Método dos Mínimos Quadrados, não importando se isso estava ou não previsto no currículo. Também não foi impeditivo que os estudantes não tivessem estudado anteriormente os conteúdos considerados pré-requisitos para o entendimento do método.

Tudo foi possível trabalhar no contexto do problema. Assim foram estudados: conceito de derivadas parciais, cálculo de derivada parcial da função potência, vetores, produto escalar, representação matricial de sistemas de equações, além do próprio método dos mínimos quadrados, necessário para o ajuste dos dados.Considero que essa primeira abordagem dos referidos conteúdos não deve ser entendida como suficiente para esgotar esses assuntos. É sempre interessante revisitar conteúdos em novos contextos. No caso dos aqui enumerados, entendo que devem ser retomados em momento oportuno de modo a propiciar o detalhamento e profundidade interessantes para a abordagem teórica do conteúdo. 


\section{Considerações Finais}

Muitos dos documentos oficiais tomados como referência para a Educação no Brasil e, em especial, para o ensino de Matemática em diferentes níveis, indicam a abordagem de problemas advindos da realidade dos alunos e o tratamento dos conteúdos de Matemática de forma contextualizada e interdisciplinar. Defende-se que "a aprendizagem em Matemática tenha a resolução de problemas, as investigações, as modelizações como pontos centrais da atividade em sala de aula e que sejam valorizadas capacidades como as de levantar hipóteses, argumentar, questionar, validar" (PIRES, p. 44).

Implantar isso é um desafio, uma vez que os currículos são estruturados em disciplinas que, muitas vezes desenvolvem suas atividades de forma independente umas das outras. Há ainda a grande preocupação dos professores em cumprir os programas no que diz respeito aos objetivos específicos e conteúdos indicados para cada ano nos documentos oficiais. O que se observa, na prática, é que parece prevalecer um modelo curricular no qual os conteúdos são organizados de forma linear e desarticulados.

Pires (2013, p.33) destaca a possibilidade de que os processos de construção de currículos levem em conta o princípio de metamorfose das redes, destacando as conexões entre temas, indicando "possibilidades de rever as organizações lineares dos conteúdos, que consideram unicamente a ideia de pré-requisito e, ao mesmo tempo, tratam dos conteúdos de forma estanque, sem articulações e desprovidos de significado".

Neste artigo trouxe uma reflexão sobre relações estabelecidas entre as práticas de Modelagem e a abordagem de conteúdos matemáticos indicados nos programas das disciplinas nas organizações curriculares. A referência para a reflexão foi uma prática de Modelagem em um curso de licenciatura, na qual foi desenvolvido um projeto temático sobre o aquecimento global, com a problematização sobre a quantificação da emissão e absorção de dióxido de carbono em um contexto específico.

A prática de Modelagem descrita e analisada é um exemplo de possibilidade de abordagem de conteúdos de Matemática de forma contextualizada, interdisciplinar, rompendo com a organização linear dos conteúdos pautada na ideia de pré-requisito. Embora todas as atividades tenham sido desenvolvidas no âmbito da disciplina "Resolução de Problemas", a abrangência do tema e a abertura dada aos participantes para problematizarem e escolherem especificamente o que iriam estudar levaram à necessidade de utilizar conceitos ligados a outras disciplinas, especialmente os de Química.

Assim pode-se dizer que houve interdisciplinaridade e, para que isso ocorresse, a participação dos estudantes, mobilizando seus próprios conhecimentos e buscando outros necessários, foi imprescindível. Os conteúdos matemáticos foram mobilizados de acordo com as necessidades que emergiram do processo de modelagem. Os que já eram conhecidos pelos estudantes foram utilizados. Outros, que não eram conhecidos, foram estudados naquele 
momento, para serem aplicados no modelo. Dessa forma adquiriram significado no contexto do tema investigado.

Destaco especialmente o rompimento com a organização linear pautada na ideia de pré-requisito. Isto se deu quando decidimos entender o modelo de absorção arbórea de $\mathrm{CO}_{2}$. Para tanto havia necessidade de fazer um ajuste de uma função de duas variáveis. Até aquele momento os estudantes tinham apenas conhecimentos de Cálculo Diferencial e Integral de funções de uma variável. Não haviam estudado o Médodo dos Mínimos Quadrados (nem para funções de uma varável), não sabiam nada sobre derivadas parciais, não tinham conhecimentos de Álgebra Linear ou vetores. Tudo isso seria necessário para fazer o ajuste. Em outras palavras, não tinham os chamados pré-requisitos. Mas era preciso entender os números que apareciam como coeficientes no modelo apresentado no artigo estudado.

Os estudantes já haviam construído seus próprios modelos para quantificar determinadas emissões de $\mathrm{CO}_{2}$ em etapa anterior do projeto. Tinham tido, portanto, contato com o processo de modelagem. A decisão não foi de simplesmente usar um modelo, mas de entender como foi construído. Talvez isso tenha motivado os alunos a buscar as ferramentas matemáticas, mesmo que para isso tivéssemos de nos distanciar temporareamente do problema original.

Os conteúdos matemáticos foram sendo introduzidos e trabalhados pela necessidade de utilizaçao para o ajuste pelo método dos mínimos quadrados. Conceitos relativos a funções de duas variáveis, como as derivadas parciais, foram abordados fazendo analogias com os correspondentes para funções de uma variável. Os estudantes não estranharam que tanta coisa nova estivesse sendo vista ao mesmo tempo. Pareceu natural. Os conteúdos tinham significado. Estavam interessados em entender o modelo.

Silva (2013), ao analisar contribuições das teorias curriculares para as discussões em Educação Matemática, se refere à aplicabilidade crítica da Matemática, segundo a qual:

Os conteúdos estariam a serviço da problemática envolvida para solucionar determinada questão. Portanto, não poderiam ser selecionados antes da própria determinação das situações que seriam estudadas. E mais, durante o processo de resolução, outros conteúdos poderiam ser abordados ou deixados de lado, desde que fique clara a aplicabilidade ou não dos mesmos. Nessa dimensão, o termo "crítico" que utilizamos refere-se às características que Skovsmose (2001a) descreveu ao definir um currículo crítico. (p.221) ${ }^{31}$

Também entre as pesquisas sobre Modelagem Matemática essa questão de trabalhar os conteúdos a partir das necessidades do processo de modelagem é muito enfatizada. Dessa forma a Modelagem pode propiciar certa flexibilização dos currículos, uma vez admite a

${ }^{31}$ A referência Skovsmose (2001a), no texto original do autor citado, aparece como Skovsmose (2001) nas referências deste artigo. 
possibilidade de inserir novos conteúdos não previstos nos programas ou, eventualmente, deixar de abordar alguns conteúdos. A possível dificuldade em cumprir programas préestabelecidos quando se pratica a Modelagem em sala de aula pode, de alguma maneira, desencorajar alguns professores, especialmente por se sentirem cobrados pelas avaliações institucionais.

No entanto as pesquisas apontam também alternativas encontradas para viabilizar a prática, mesmo em contextos restritivos (Franchi, 2019). Ainda, Pires (2013) adverte que matrizes elaboradas para avaliação não podem substituir projetos curriculares. Meu entendimento é de que não se deve escolher entre aplicar ou não uma proposta pedagógica apenas pela facilidade de cumprir ou não programas pré-estabelecidos. Pires (2013, p. 48) considera pertinente avaliar questões como: "Não estariam os currículos de Matemática excessivamente carregados de conteúdos? Não poderíamos ser mais comedidos e redimensioná-los, optando pela lógica do “menos”, mas bem feito?” (grifos da autora).

Uma prática de Modelagem (como a aqui descrita) pode propiciar muito mais do que a aprendizagem da Matemática. Por meio dela os estudantes podem desenvolver potencialidades como a capacidade de investigar, problematizar, argumentar e procurar alternativas para resolução de problemas. Podem ainda usar seus conhecimentos para compreender a realidade e refletir criticamente sobre ela. Finalizo com uma citação de Meyer, Caldeira e Malheiros (2011, p. 40) "Nós, professores de Matemática, devemos estar dispostos a discutir, em nossas escolas, problemas advindos da realidade dos alunos. Problemas de fora da escola. E isso, se algum dia for incorporado nas nossas escolas, mudará muito nossas práticas educacionais."

\section{Referências}

BARboSA, J. C. Modelagem Matemática na sala de aula. Perspectiva. Erechin (RS), v.7, n. 98, p. 65-74, 2003.

BASSANEZI, R. C. Ensino-aprendizagem com Modelagem Matemática. São Paulo: Contexto. 2002.

BIEMbengut, M. S. Modelagem Matemática no ensino fundamental. Blumenau: Edifurb, 2014.

BIEMBEnguT, M. S. Modelagem na Educação Matemática e na Ciência. São Paulo: Editora Livraria da Física. 2016.

BURAK, D. Modelagem Matemática e a sala de aula. In: Encontro Paranaense de Modelagem em Educação Matemática. 1., 2004. Londrina. Anais.Londrina: UEL, 2004. 1. CDROM.

BURAK, D. Modelagem Matemática sob um olhar de Educação Matemática e suas implicações para a construção do conhecimento matemático em sala de aula. Revista de 
Modelagem na Educação Matemática, Vol. 1, No. 1, 10-27, 2010. Disponível em http://proxy.furb.br/ojs/index.php/modelagem/article/view/2012/1360

D’AMBROSIO, U. Da realidade à ação: reflexões sobre educação e matemática. Campinas, SP: Sammus Editorial, 1986.

D’AMBROSIO, U. Educação Matemática: da teoria à prática. Campinas, SP: Papirus, 1996.

FERREIRA, M. S. O Currículo e sua trama. In: ALMEIDA, M. D. (Org.) Currículo como artefato social. EDFRN, 2000, p. 13-25.

FERREIRA, M.S. Currículo: que conteúdos são ensinados e aprendidos? Linguagens, Educação e Sociedade. Teresina, Ano 12, n. 17, jul./dez. 2007.

FRANCHI, R. H. O. L. Modelagem Matemática como estratégia de aprendizagem do Cálculo Diferencial e Integral nos cursos de Engenharia. 1993. Dissertação (Mestrado em Educação Matemática). Universidade Estadual Paulista, Rio Claro, 1993.

FRANCHI, R. H. O. L. Uma proposta curricular de matemática para cursos de engenharia utilizando modelagem matemática e informática. Tese (Doutorado em Educação Matemática). 189f. Universidade Estadual Paulista, Rio Claro, 2002.

FRANCHI, R. H. O. L., BEAN, D. W. O desenvolvimento de uma atividade de modelagem para o ensino fundamental em consonância com os Parâmetros Curriculares Nacionais. In: Conferência Nacional sobre Modelagem na Educação Matemática, 7, Belém-PA. AnaisUniversidade Federal do Pará - Pará, 2011.

FRANCHI, R. H. O. L., Algumas lições de Bassanezi sobre a Modelagem em contextos educacionais: reflexões sobre a condução de um projeto em um curso de Licenciatura. In: BIEMBENGUT, M. S.; VIEIRA, E.; POMPEU JR, G. (Org.). Modelagem (em) comum: um tributo a Rodney Carlos Bassanezzi. 1.ed. Santo André: Universidade Federal do ABC, 2013, v. 1, p. 133-154.

FRANCHI, R. H. O. L., Modelagem Matemática e projetos temáticos na Educação Básica: exemplos de duas maneiras de conduzir. In: Conferência Interamericana de Educação Matemática, 2019, Medelin. Anais da XV CIAEM, 2019.

LÉVY, P. Cibercultura. São Paulo: Editora 34 Ltda, 1999.

MACHADO, N. J. Epistemologia e Didática: as concepções de conhecimento e inteligência e a prática docente. São Paulo: Cortez, 1995.

MACHADO, N. J. Educação: projetos e valores. 3. ed. São Paulo: Escrituras, 2000.

MEYER, J. F. da C. de A.; CALDEIRA, A. D.; MALHEIROS, A. P dos S. Modelagem em Educação Matemática. Belo Horizonte: Autêntica Editora, 2011.

PIRES, C. M. C. Currículo, avaliação e aprendizagem matemática na educação básica. In: INEP (Org.). Avaliações da Educação Básica em debate: Ensino e matrizes de referências das avaliações em larga escala. INEP. 1ed. Brasília: INEP, 2013, v. 1, p. 3154 . 
SILVA, M. A. Contribuições Contemporâneas para as Discussões Curriculares em Educação Matemática: a teoria crítica pós-moderna. Alexandria: Revista de Educação em Ciência e Tecnologia. Florianópolis, v.6, n.1, p. 205-233, 2013.

SKOVSMOSE, O. Cenários de Investigação. Boletim de educação matemática. Rio Claro, n.14, p.66-91, 2000.

SKOvSMOSE, O. Educação Matemática Crítica: a questão da democracia. Campinas: papiros, 2001.

SOARES, C. P. B.; OLIVEIRA, M. L. R. Equações para estimar a quantidade de carbono na parte aérea de árvores de eucalipto em Viçosa, Minas Gerais. Árvore, Viçosa-MG: Sociedade de Investigações Florestais. V26, n.5, p.533-539, 2002.

\section{Biografia Resumida}

Regina Helena de Oliveira Lino Franchi: Bacharel e Licenciada em Matemática pela UNICAMP. Mestre e Doutora em Educação Matemática pela UNESP- Rio Claro. Professora da Universidade Federal do ABC (UFABC). Participa dos Grupos de Pesquisa: (1) Estudos e Pesquisa em Educação em Ciências, Matemática e Sexualidade (GECIMAS - UFABC) e (2) Tendências na Educação Matemática (GEPTEMa - UFABC)

Lattes: http://lattes.cnpq.br/3417222098702995

Contato: regina.franchi@ufabc.edu.br 